\title{
ADENOVIRUS-MEDIATED GLIAL CELL LINE-DERIVED NEUROTROPHIC FACTOR GENE DELIVERY REDUCES MOTOR NEURON INJURY AFTER TRANSIENT SPINAL CORD ISCHEMIA IN RABBITS
}

Masahiro Sakurai, MD ${ }^{\mathrm{a}, \mathrm{d}}$

Koji Abe, $\mathrm{MD}^{\mathrm{b}}$

Takeshi Hayashi, MD

Yasuhiro Setoguchi, MD $^{c}$

Gen-ya Yaginuma, $\mathrm{MD}^{\mathrm{d}}$

Taiichiro Meguro $\mathrm{MD}^{\mathrm{d}}$

Koichi Tabayashi, MD
Objective: Glial cell line-derived neurotrophic factor (GDNF) has protective effects on various injuries involving the central and peripheral nervous systems in vitro and vivo. However, the possible protective effect of GDNF on spinal cord ischemia and the exact mechanism involved in the ameliorative effect of GDNF on ischemic spinal cord injuries are not fully understood. Therefore, we investigated the possible protective effect of the adenovirusmediated GDNF gene delivery on transient spinal cord ischemia in rabbits.

Methods: The adenoviral vector (lacZ gene as a control or GDNF gene contained) was injected directly into the lumbar spinal cord via a needle inserted into the dorsal spine 2 days before the animal was subjected to $15 \mathrm{~min}$ utes of spinal cord ischemia induced by infrarenal aortic occlusion. In situ terminal deoxynucleotidyl transferase (TdT)-mediated dUTP-biotin nickend labeling (TUNEL staining) was performed, and temporal profiles of the GDNF and caspase-3 (caspase-3 is the marker of apoptotic change) immunoreactivity were investigated.

Results: In the control rabbit, the majority of motor neurons showed selective cell death at 7 days of reperfusion. Immunocytochemistry showed that in situ TUNEL staining was selectively detected at 2 days of reperfusion in motor neuron nuclei. GDNF and caspase-3 were selectively induced in the motor neuron cells at 8 hours of reperfusion. In the GDNF-treated group, a large population of motor neuron cells was still surviving at 7 days after having been subjected to 15 minutes of ischemia. Unlike the control group, the GDNF-treated group expressed GDNF persistently. Induction of TUNEL staining and immunoreactivity for caspase-3 were greatly reduced by the GDNF treatment.

Conclusion: These results suggest that the reduction in motor neuron death by GDNF was greatly associated with a reduction in DNA fragmentation and apoptotic signals of the caspase- 3 cascade; they further suggest a great potential for gene therapy for paraplegic patients in the future. ( $\mathrm{J}$ Thorac Cardiovasc Surg 2000;120:1148-57)
From the Department of Cardiovascular Surgery, Graduate School of Medicine, Tohoku University, ${ }^{a}$ Sendai; the Department of Neurology, Okayama University School of Medicine, ${ }^{b}$ Okayama; the Department of Respiratory Medicine, Juntendo University School of Medicine, ${ }^{\mathrm{c}}$ Tokyo; and the Division of Heart Institute,

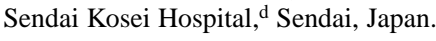

Received for publication Jan 7, 2000; revisions requested March 17, 2000; revisions received April 13, 2000; accepted for publication Aug 29, 2000.

Address for reprints: Masahiro Sakurai, MD, Department of Cardiovascular Surgery, Graduate School of Medicine, Tohoku University, 1-1 Seiryo-machi, Aoba-ku, Sendai 980-8574, Japan.

Copyright (C) 2000 by The American Association for Thoracic Surgery

$0022-5223 / 2000 \$ 12.00+0 \quad \mathbf{1 2 / 1 / 1 1 1 1 7 8}$

doi: $10.1067 / \mathrm{mtc} .2000 .111178$
Daraplegia is a catastrophic complication of thoracic aortic surgery. Various methods of spinal cord protection such as temporary shunts, partial bypass, and hypothermia have been suggested to prevent this complication. However, no reliable method has been developed that totally prevents the development of paraplegia. ${ }^{1}$ The incidence of paraplegia ranges from $2.9 \%$ to $23 \%^{2}$ in operations on the thoracic aorta. The mechanism of spinal cord injury has been thought to involve tissue ischemia, and the spinal motor neuron cells are vulnerable to ischemia. However, the exact mechanism is not fully understood.

Glial cell line-derived neurotrophic factor (GDNF) has been recently isolated as a peptide protein of sur- 
vival and neurite outgrowth of dopaminergic and motor neurons, as well as peripheral sensory and sympathetic neurons, ${ }^{3,4}$ and is structurally related to members of the transforming growth factor $\beta$ superfamily. ${ }^{5}$ It has been reported that GDNF has protective effects on various injuries to the central and peripheral nervous systems in vitro and vivo. ${ }^{4,6,7} \mathrm{We}^{8}$ have demonstrated that topical application of GDNF significantly ameliorates brain edema formation in the ischemic rat brain in association with a reduction in TUNEL staining (terminal deoxynucleotidyl transferase [TdT]-mediated dUTP-biotin nick-end labeling). However, such proteins are greatly limited for use in ischemic neurons as pharmaceutical agents because it is difficult for them to directly enter the spinal cord due to the nature and size of the molecules (protein/peptide). ${ }^{9}$

Recent studies have suggested that the use of replication-defective adenoviral vectors has provided a novel strategy for direct gene transfer into the central nervous system. ${ }^{10}$ Further, an adenoviral vector can transduce a given gene into nonproliferating cells such as neuronal cells. ${ }^{11} \mathrm{We}^{12}$ previously have demonstrated that the transfer and expression of the lacZ gene in motor neuron cells suggests the onset of apoptosis. Furthermore, $w^{8}$ have demonstrated that GDNF gene delivery reduces ischemic brain injury with a reduction of TUNEL staining and the immunohistochemistry for caspases. However, a possible protective effect of GDNF on spinal cord ischemia and the exact mechanism of the ameliorative effect of GDNF on ischemic spinal cord injuries are not fully understood. Therefore, we investigated the possible protective effect of adenovirus-mediated GDNF gene delivery on transient spinal cord ischemia in rabbits.

\section{Materials and methods}

Animal models. Forty-one domesticated white rabbits from Japan (Funakoshi, Japan), weighing 2 to $3 \mathrm{~kg}$, were used in this study and were divided into 3 groups: those with sham operation 2 days after the vehicle was injected into the spinal cord (sham control, $n=3$ ), those with 15 minutes of spinal cord ischemia 2 days after the lacZ gene was injected into the spinal cord (lacZ-treated group, $n=19$ ), and those with a 15-minute ischemic insult 2 days after the GDNF gene was injected into the spinal cord (GDNF-treated group, $\mathrm{n}=$ 19). Anesthesia was induced with intramuscular administration of ketamine at a dose of $50 \mathrm{mg} / \mathrm{kg}$ and maintained with $2 \%$ halothane inhalation. A 5F thermodilution catheter (405; B. Braun Melsungen AG, Melsungen, Germany) was inserted through the femoral artery and advanced from the inguinal band $15 \mathrm{~cm}$ forward into the abdominal aorta. Preliminary investigation confirmed that the balloon on the distal end of the thermodilution catheter was positioned 0.5 to $1.5 \mathrm{~cm}$ just distal to the left renal artery. During the experiment, the aortic pressure was continuously monitored from both the proximal and distal positions of the distal balloon. The body temperature was monitored with a rectal thermistor and maintained at $37^{\circ} \mathrm{C}$ with the aid of a heating pad during the operation and subsequent ischemia. The animals were then allowed free access to water and food at the ambient temperature. They were put to death with deep anesthesia by means of sodium pentobarbital ( $100 \mathrm{mg} / \mathrm{kg}$ intravenously) at 8 hours $(\mathrm{n}=3), 1$ day $(\mathrm{n}=3), 2$ days $(\mathrm{n}=5)$, and 7 days $(\mathrm{n}=5)$ after reperfusion. In the sham control group and in the 0-hour group, the animals were put to death after insertion of the catheter into the abdominal aorta without inflating the balloon. The tissue samples for immunohistochemistry were frozen in powdered dry ice and stored at $-80^{\circ} \mathrm{C}$. The samples for histologic examination were fixed by immersing them in $4 \%$ paraformaldehyde in a $0.1 \mathrm{~mol} / \mathrm{L}$ concentration of phosphate buffer and then stored at $4^{\circ} \mathrm{C}$ for 1 week. They were then cut transversely at about the L2 or L3 level and finally embedded in paraffin. In the experiment, the rabbits were treated in accordance with the Declaration of Helsinki and the "Guiding Principles in the Care and Use of Animals." Also, the experimental and animal care protocol was approved by the Animal Care Committee of the Tohoku University School of Medicine.

Neurologic assessment. Neurologic function was observed at 2 and 7 days after the procedure, and animals were classified into a 5-point scale according to the method of Johnson, Kraimer, and Graeber ${ }^{13}$ : $0=$ hind-limb paralysis; 1 = severe paraparesis; 2 = functional movement, no hop; $3=$ ataxia, disconjugate hop; $4=$ minimal ataxia; $5=$ normal function. Two individuals, without knowledge of the treatment, independently graded the neurologic function. Statistical analyses of the neurologic scores were performed with the Mann-Whitney $U$ test.

Adenoviral vector constructs. The recombinant adenoviral vector used in this study was based on the type 5 adenovirus, which was essentially the same as that in previous reports. ${ }^{14,15}$ In brief, the E3 region of the adenovirus genome was deleted, and a cassette containing the complementary DNA for rat GDNF or the Escherichia coli lacZ gene (used as a control vector) driven by a cytomegalovirus promoter and simian virus 40 polyadenylation signal was inserted into the E1 region of the adenovirus genome by homologous recombination. With this promoter, the rat GDNF or $E$ coli lacZ gene of the episomally located adenovirus vectors could be transcribed as messenger RNA in the nucleus, and then the mRNA could be translated into the protein in cytoplasm. The adenoviral vector, designated as Ad-GDNF or Ad-lacZ, was propagated in 293 cells (CRL1573; American Type Collection) and purified and titered as previously described. ${ }^{14,15}$

In vivo gene transfer. Two days before spinal cord ischemia, the adenoviral vector was inoculated. With immobilization using a stereotactic apparatus, either Ad-GDNF or Ad-lacZ $\left(2.5 \times 10^{9}\right.$ plaque-forming units in a $5-\mu \mathrm{L}$ vector vehicle consisting of $10 \mathrm{mmol} / \mathrm{L}$ Tris-HCl, $\mathrm{pH} 7.4,1 \mathrm{mmol} / \mathrm{L}$ 
Table I. Neurologic score at 2 and 7 days after 15 minutes of ischemia in animal groups treated with lacZ or GDNF before ischemia

\begin{tabular}{lccccc}
\hline & & \multicolumn{2}{c}{ LacZ } & \multicolumn{2}{c}{ GDNF } \\
\cline { 3 - 6 } Animal & Sham & $2 d$ & $7 d$ & $2 d$ & 5 \\
\hline 1 & 5 & 5 & 3 & 5 & 3 \\
2 & 5 & 4 & 2 & 5 & 4 \\
3 & 5 & 4 & 3 & 4 & 4 \\
4 & 5 & 3 & 2 & 4 & 3 \\
5 & 5 & $4.2 \pm 0.83$ & $2.4 \pm 0.55^{*}$ & $4.5 \pm 0.55$ & $3.8 \pm 0.84$ \\
Mean \pm SD & $5 \pm 0$ & &
\end{tabular}

$* P=.021$ compared with 7 days after procedure, lacZ- and GDNF-treated group.

$\mathrm{MgCl}^{2}$, and $10 \%$ glycerol) was administered into the dorsal white matter via the L3 intervertebral disk to a depth of 20 $\mathrm{mm}$ from the skin surface. A $10-\mu \mathrm{L}$ sterile Hamilton syringe (the Gasthghit High-performance Syringe, Hamilton, Reno, $\mathrm{Nev}$ ) and a 26-gauge needle (0.47-mm outer diameter) were used. In the sham control group, 3 animals that were injected with vehicle $(5 \mu \mathrm{L}$ of vehicle consisting of $10 \mathrm{mmol} / \mathrm{L}$ Tris$\mathrm{HCl}, \mathrm{pH} \mathrm{7.4,} 1 \mathrm{mmol} / \mathrm{L} \mathrm{MgCl}_{2}$, and $10 \%$ glycerol) were allowed to recover immediately after the sham operation. Preliminary investigation confirmed that the end of the needle was positioned 1 to $3 \mathrm{~mm}$ just dorsal to the central canal of the spinal cord. The injection $(5 \mu \mathrm{L})$ was slowly completed over 10 minutes. During the injection, the needle was withdrawn gradually at a rate of $3.5 \mathrm{~mm}$ in 10 minutes and was finally removed after 10 minutes.

Histologic study. The sections were stained with hematoxylin-eosin and examined by light microscopy. An observer, unaware of the animal group and neurologic outcome, examined each slide. With hematoxylin-eosin staining, the cells were considered "dead" if the cytoplasm was diffusely eosinophilic and "viable" if the cells demonstrated basophilic stippling (that is, if they contained Nissl substance). The spinal cords were removed, fixed by immersion in $4 \%$ paraformaldehyde in $0.1 \mathrm{~mol} / \mathrm{L}$ phosphate buffer for 7 days, and then embedded in paraffin. The number of intact large motor neuron cells in the Rexed laminae VII, VIII, and IX was counted. Statistical analyses of the number of motor neurons were performed with the MannWhitney $U$ test.

TUNEL staining. To detect DNA fragmentation in the nuclei of the cells, we applied a modified TUNEL reaction to the cryosections according to our previously reported method ${ }^{16}$ using a kit (4810-30-K; Trevigen, Inc, Gaithersburg, Md). After deparaffinizing, the nuclei of the tissue sections were stripped of proteins by incubation with $20 \mu \mathrm{g} / \mathrm{mL}$ proteinase $\mathrm{K}$ for 10 minutes. After being treated with $0.3 \%$ hydrogen peroxide $\left(\mathrm{H}_{2} \mathrm{O}_{2}\right)$ in distilled water for 5 minutes, they were incubated with TdT and biotinylated dUTP in a TdT buffer in a humidified chamber at $37^{\circ} \mathrm{C}$ for 120 minutes. Further incubation with peroxidase-conjugated streptavidin was carried out for $30 \mathrm{~min}-$ utes at room temperature. The slices were colored with diaminobenzadine $(\mathrm{DAB}) / \mathrm{H}_{2} \mathrm{O}_{2}$ solution and then counterstained with methyl green. To determine the number of motor neurons that underwent apoptosis, we counted the motor neu- rons that were positive or negative in the TUNEL staining. Statistical analyses of the number of TUNEL-positive motor neurons were performed with the Mann-Whitney $U$ test.

GDNF and caspase-3 immunocytochemistry. We also performed an immunohistochemical study to investigate the change in the expression of GDNF and caspase-3. The frozen sections, $10 \mu \mathrm{m}$ in thickness, were fixed in acetone, rinsed in a $0.1 \mathrm{~mol} / \mathrm{L}$ concentration of phosphate-buffered saline solution for 20 minutes, and blocked in $2 \%$ normal horse serum for 2 hours at room temperature. They were then incubated with primary antibodies in $10 \%$ normal horse serum or $10 \%$ normal rabbit serum and $0.3 \%$ Triton-X 100 octylphenoxypolyethoxyethanol (Union Carbide Corporation, Danbury, Conn) for 20 hours at $4^{\circ} \mathrm{C}$. The primary antibodies used were as follows: mouse monoclonal antibody against GDNF (MAB212; R \& D Systems, Inc, Minneapolis, Minn) and goat polyclonal antibody against caspase-3 (SC 1217; Santa Cruz Biotechnology, Inc, Santa Cruz, Calif), and each dilution was as follows: antibody against GDNF of 1:200 and that against caspase-3 of 1:200.

After endogenous peroxidase activity had been quenched by exposing the slides to $0.3 \% \mathrm{H}_{2} \mathrm{O}_{2}$ and $10 \%$ methanol for 20 minutes, the slides were washed in phosphate-buffered saline solution. They were then incubated for 3 hours with biotinylated anti-mouse immunoglobulin G (PK-6102; Vector Laboratories, Burlingame, Calif) and biotinylated anti-goat immunoglobulin G (PK-6105; Vector Laboratories) in a 1:200 dilution of phosphate-buffered saline solution containing $0.018 \%$ normal horse or rabbit serum, respectively. Subsequently, they were incubated with avidin-biotin-horseradish peroxidase complex (PK-6102; Vector Laboratories). The slices were colored with a $\mathrm{DAB} / \mathrm{H}_{2} \mathrm{O}_{2}$ solution, and the cytoplasms were counterstained with hematoxylin. So that the specific binding of the antibody to the protein could be ascertained, a set of sections were stained in a similar way without the primary antibody. The staining was categorized into 4 grades in the following manner: no stain $(-)$, slightly stained $( \pm)$, moderately stained $(+)$ or densely stained $(2+)$.

\section{Results}

Neurologic outcome. The results are summarized in Table I. There were no neurologic changes in the sham 

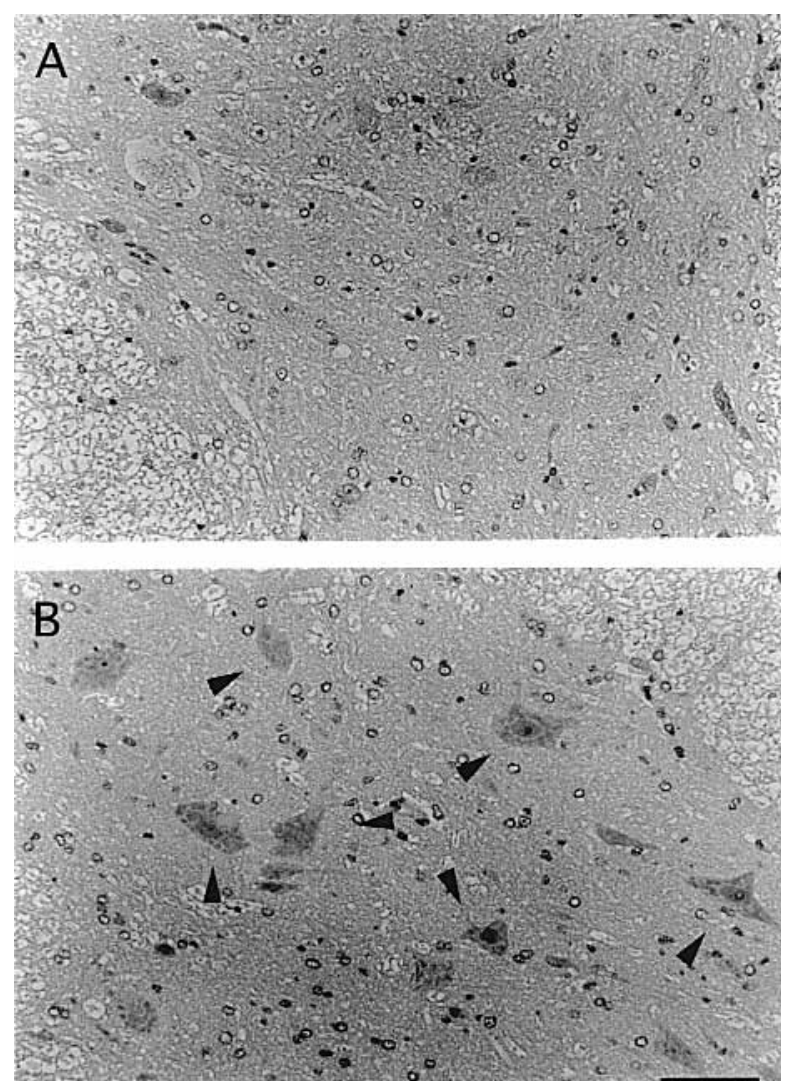

Fig 1. Representative photographs of spinal cord sections stained with hematoxylin-eosin at 7 days after reperfusion. After being subjected to 15 minutes of ischemia 2 days before the lacZ treatment, about $70 \%$ of the motor neuron cells in the ventral gray matter were lost at 7 days of reperfusion (A). After being subjected to 15 minutes of ischemia 2 days before the GDNF treatment, almost all of the motor neuron cells were preserved at 7 days of reperfusion (B, arrowheads). Bar $=100 \mu \mathrm{m}$.

control group or at 0 hours, 8 hours, and 1 day of the lacZ- and GDNF-treated groups. In the lacZ-treated group at 2 days after the procedure $(n=5), 2$ rabbits $(40 \%)$ were normal (grade 5), $2(40 \%)$ had minimal ataxia (grade 4), and 1 (20\%) had ataxia (grade 3). In the lacZ-treated group at 7 days after the procedure $(\mathrm{n}$ $=5), 3$ rabbits $(60 \%)$ did not hop (grade 2 ) and $2(40 \%)$ had ataxia (grade 3 ).

In the GDNF-treated group at 2 days after the procedure $(\mathrm{n}=5), 3$ rabbits $(60 \%)$ were normal (grade 5) and $2(40 \%)$ had minimal ataxia (grade 4). In the GDNFtreated group at 7 days after the procedure $(n=5), 1$ rabbit (20\%) was normal (grade 5), 2 (40\%) had minimal ataxia (grade 4), and $2(40 \%)$ had ataxia (grade 3). There was a significant difference in the Johnson neurologic scores at 7 days after the procedure between the GDNF-treated group and the lacZ-treated group (3.8 \pm

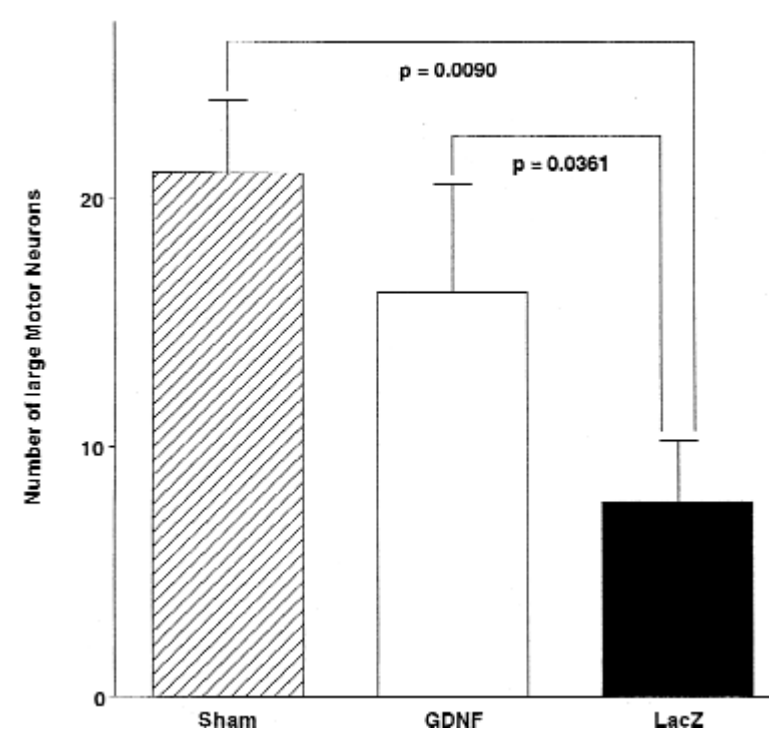

Fig 2. Number of intact motor neurons in the sham control group and in the lacZ- and GDNF-treated groups at 7 days after reperfusion.

0.84 vs $2.4 \pm 0.55 ; P=.021$ ). Fifteen minutes of ischemia 2 days after the GDNF pretreatment with the adenoviral vector did not affect the neuronal function.

Histologic study. The results of the cell count in Rexed laminae VII, VIII, and IX in the paraffin sections obtained from this study in animals are shown in Figs 1 and 2. Following the sham control group, no significant change was seen in the motor neurons $(21.2 \pm 3.0)$ (Fig 2). There were no histologic changes at 0 hours, 8 hours, and 1 and 2 days of the lacZ- and GDNF-treated groups. After the 15 minutes of ischemia in the lacZ treatment group on the seventh day of reperfusion, about $70 \%$ of the motor neuron cells in the ventral gray matter were lost (Fig 1, A, and Fig 2). The damage to the motor neuron cells after the GDNF treatment was only slight, and large populations of cells were preserved (Fig 1, B, arrowheads, and Fig 2). Small motor neurons and intermediate neurons survived the ischemia. The dorsal horn neurons were intact after 15 minutes of ischemia (data not shown). A significant recovery in the number of motor neuron cells was found in GDNF-treated group as compared with the lacZ-treated group 7 days after the procedure (16.2 \pm 4.8 vs $7.8 \pm 2.6 ; P=.0361$ ) (Fig 2).

TUNEL staining. Photographs of TUNEL staining of the spinal cords are shown in Fig 3. There were no TUNEL reactions in motor neurons in the sham control group and at 0 hours, 8 hours, and 1 day in the lacZand GDNF-treated groups (data not shown). Two days after the ischemic insult, about $50 \%$ of the positive 

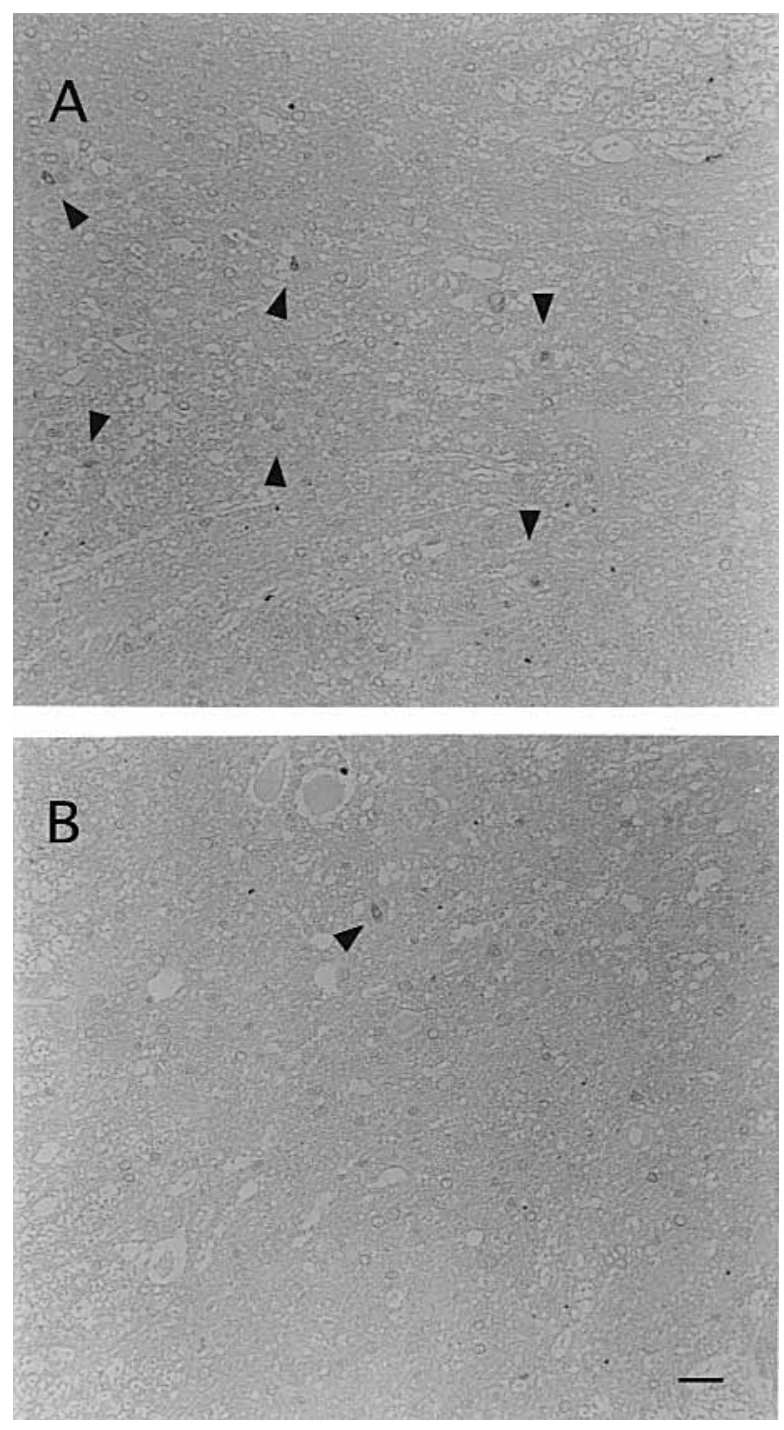

Fig 3. TUNEL staining in the ventral gray matter of the lacZtreated spinal cord (A) and GDNF-treated spinal cord (B) after 2 days of reperfusion following 15 minutes of ischemia. Arrowheads show the motor neuron cell nuclei that have positive TUNEL staining. Bar $=100 \mu \mathrm{m}$.

staining in the motor neuron cells in the ventral gray matter were detected to have brown with granular pattern (Fig 3,A), indicating the cells that were undergoing double-strand DNA breaks mainly associated with apoptosis in lacZ-treated group. The neurons in the dorsal horn of the gray matter and white matter were not positive for TUNEL staining (data not shown).

In the GDNF-treated group at 2 days after the procedure, a few of the motor neurons were positive for TUNEL staining (Fig 3, B). For quantitative measurement, the number of motor neurons that were positive or negative in TUNEL was recorded in each specimen

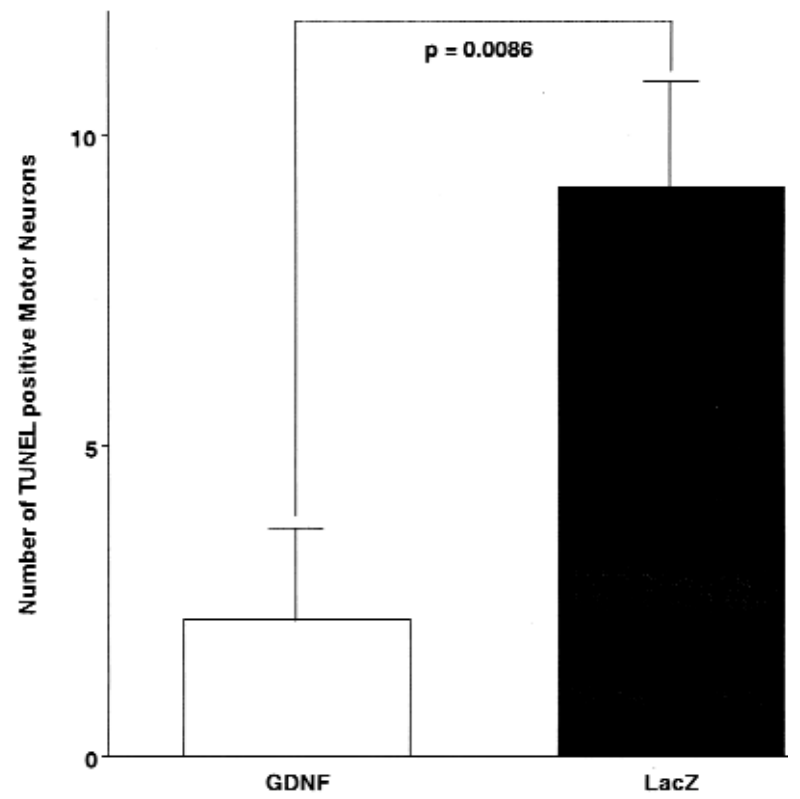

Fig 4. Number of TUNEL-positive motor neurons in the lacZ- and GDNF-treated groups at 2 days after reperfusion.

in a blind fashion (Fig 4). There was a significant difference in the number of TUNEL-positive motor neurons at 2 days after the procedure between the GDNFtreated and lacZ-treated groups $(2.2 \pm 1.3$ vs $9.2 \pm 1.5$; $P=.0086)$.

Immunohistochemical study. The immunoreactive GDNF and caspase-3 sections from the spinal cords are shown in Figs 5 and 6. The spinal cords of sham control and lacZ-treated animals at 0 hour did not show GDNF (Fig 5, D, Table II) and caspase-3 (Fig 6, D, Table II) antigen immunoreactivity in any of the cells. In the lacZ-treated group, the motor neurons selectively showed strong immunoreactivity for GDNF (Fig 5, $E$, Table II) and caspase-3 (Fig 6, E, Table II) antigen by 8 hours of reperfusion after 15 minutes of ischemia. Immunoreactivity of the motor neuron cells for GDNF (Fig 5, F, Table II) and caspase-3 (Fig 6, F, Table II) antigen were almost lost in the motor neurons by 1,2 , and 7 days. However, the spinal cords of the GDNFtreated animals at 0 hour already showed GDNF in the motor neuron cells (Fig 5, A, Table II) and selectively showed a strong immunoreactivity for GDNF by 8 hours of reperfusion (Fig 5, B, Table II), and the induction was sustained until 7 days of reperfusion (Fig 5, $C$, Table II). On the other hand, in the spinal cords of the GDNF-treated group, a few motor neurons showed caspase-3 (Fig 6, B, Table II) antigen immunoreactivity.

\section{Discussion}

$\mathrm{We}^{12,16}$ previously demonstrated delayed and selective motor neuron death in the lumbar region of the rab- 
bit spinal cord with the same reproducible model. Fifteen minutes of ischemia is a relatively short ischemic period in comparison with those of previously reported models, ${ }^{13}$ and after the ischemia, delayed and selective motor neuron damage was observed only after 7 days of reperfusion in this model. ${ }^{12,16}$ This phenomenon is known as selective neuronal death in motor neuron cells after spinal cord ischemia. ${ }^{12,16}$

Many recent studies on ischemic cerebrovascular disease have revealed two major ways for neuronal cell death to occur: necrosis and apoptosis. ${ }^{9}$ Necrosis usually occurs after acute ischemia, due to a reduction in the tissue ATP level accompanied by edema formation and concomitant death of glial and vascular cells. In contrast, neuronal apoptosis occurs days after ischemia without a reduction in the ATP level, nor with edema formation and concomitant death of glial and vascular cells. Our previous study reported that the induction of CPP32 (caspase-3) antigen in ischemic spinal motor neurons was related to the apoptosis of cells, which eventually die. ${ }^{17}$ In any event, some putative protective proteins such as neurotrophic factors and heat shock protein may prevent this neuronal death if the proteins can effectively work under emergency conditions such as ischemia. ${ }^{9,16}$ We previously demonstrated selective induction of GDNF and RET (REarranged during Transfection) in motor neurons at 8 hours of reperfusion after 15 minutes of ischemia in rabbits. ${ }^{18}$ These results may be related to the transient functional recovery of neurons after ischemia. However, the immunoreactivity of motor neuron cells for GDNF and RET returned to the sham control level by day 1 and almost all of the motor neurons eventually died.

In the present study, we demonstrated that about $70 \%$ of motor neurons in the spinal cord were selectively lost by 7 days after transient ischemia, and that was in accordance with our previous report. ${ }^{12,16}$ On the other hand, the TUNEL study revealed that about $50 \%$ of motor neurons had breaks in the genomic DNA at 2 days (Fig 3). It is known that nuclei of neurons undergoing apoptosis show positivity with TUNEL staining and have granular pattern; however, those with necrosis show slight staining with a homogeneous pattern. ${ }^{19}$ Because the nuclei at 2 days after ischemia in this study were densely stained in a granular pattern (Fig 2, B), the motor neurons were suggested to be undergoing apoptosis. In addition, the neuronal cells showed some morphologic features of apoptosis with hematoxylineosin staining (Fig 1,C). Through induction of caspase-3, as will be described in detail later, we could at least infer the involvement of apoptotic machinery in the motor neuron death in this model.
Table II. Summary of the GDNF and caspase-3 expression in lacZ- or GDNF-treated spinal cords

\begin{tabular}{cccccc}
\hline & \multicolumn{2}{c}{ LacZ-treated } & & \multicolumn{2}{c}{ GDNF-treated } \\
\cline { 2 - 3 } \cline { 5 - 6 } & GDNF & Caspase-3 & & GDNF & Caspase-3 \\
\hline $0 \mathrm{~h}$ & - & - & & +++ & - \\
$8 \mathrm{~h}$ & ++ & $2+2+2+$ & & $2+2+2+$ & \pm \pm \pm \\
$1 \mathrm{~d}$ & - & - & & $2+2+2+$ & - \\
$2 \mathrm{~d}$ & - & - & $2+2+2+$ & - \\
& - & - & & $2+2+$ & - \\
$7 \mathrm{~d}$ & - & - & & $2+2+2+$ & - \\
& - & - & & ++ & - \\
\hline
\end{tabular}

The staining was categorized as follows: no staining $(-)$; slight $( \pm)$; moderate (+); dense $(2+) . \mathrm{N}=3$ at sham, 8 hours, and 1 day aftter reperfusion; $\mathrm{n}=$ 5 at 2 and 7 days after reperfusion.

Some trophic factors are known to be up-regulated in the peripheral nerves after axotomy in adult mammals. ${ }^{20}$ The survival of adult motor neurons after axotomy and their death after avulsion may reflect the availability of local sources of GDNF in the axotomized peripheral nerves. ${ }^{21}$ Several clinical trials testing systemic GDNF treatment have mixed results, with some showing reduction in the disease progression, ${ }^{22,23}$ while others demonstrated little or no efficacy. ${ }^{24}$ In some cases serious adverse side effects were also reported..$^{25}$ The poor effectiveness of systemic GDNF treatment may be caused by the short serum half-life, targeting of inappropriate sites, and the blood-brain barrier.

In recent years, the use of replication-defective adenoviral vectors has provided a novel strategy for direct gene transfer into the brain. ${ }^{10,11}$ Initial experimental models of gene transfer into the brain were performed with replication-defective or latency-prone neurotrophic viruses such as the herpes simplex virus type. ${ }^{26}$ Although herpes virus vectors can carry a relatively large gene up to $36 \mathrm{~kb}$, cytopathogenicity such as neuronal death may be a major disadvantage. ${ }^{27}$ Retroviral vectors also have the potential of delivering genes into the neurons. ${ }^{28}$ However, retroviral vectors do not infect nondividing cells such as neurons, and in vivo risks such as mutagenesis and tumorigenesis are also indicated. ${ }^{27}$ Direct injection of plasmid vector with or without conjugation of liposome also carries genes to the brain. ${ }^{29}$ However, efficacy of gene expression is low. ${ }^{27}$

The advantageous feature of adenoviral vectors is that they are capable of infecting a variety of terminally differentiated cell types such as neurons and muscles. $^{27}$ It is generally considered that the ischemic spinal cord usually has a translational problem of gene expression and cannot effectively produce protein even if the mRNA is present. ${ }^{9}$ Our present results show that the motor neurons in the ventral horn can effectively 

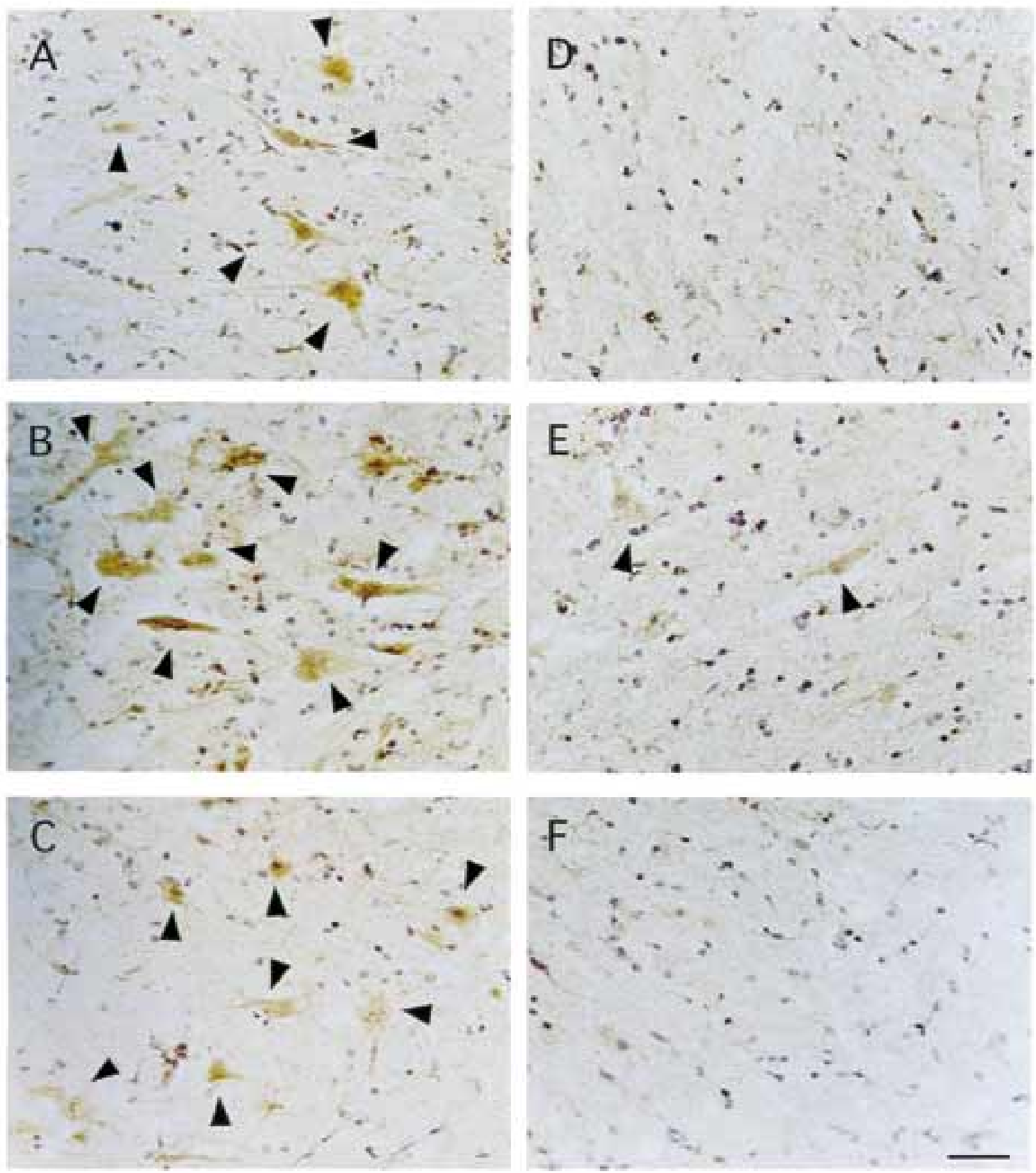

Fig 5. Immunostaining against GDNF in the motor neurons of the GDNF- or lacZ-treated groups in a sham-operated spinal cord (A and $\mathbf{D})$, at 8 hours $(\mathbf{B}$ and $\mathbf{E}), 1$ day (F, lacZ-treated group), and 7 days (C, GDNF-treated group) of reperfusion following 15 minutes of ischemia. Arrowheads show motor neurons expressing immunoreactive GDNF. Bar $=100 \mu \mathrm{m}$. 

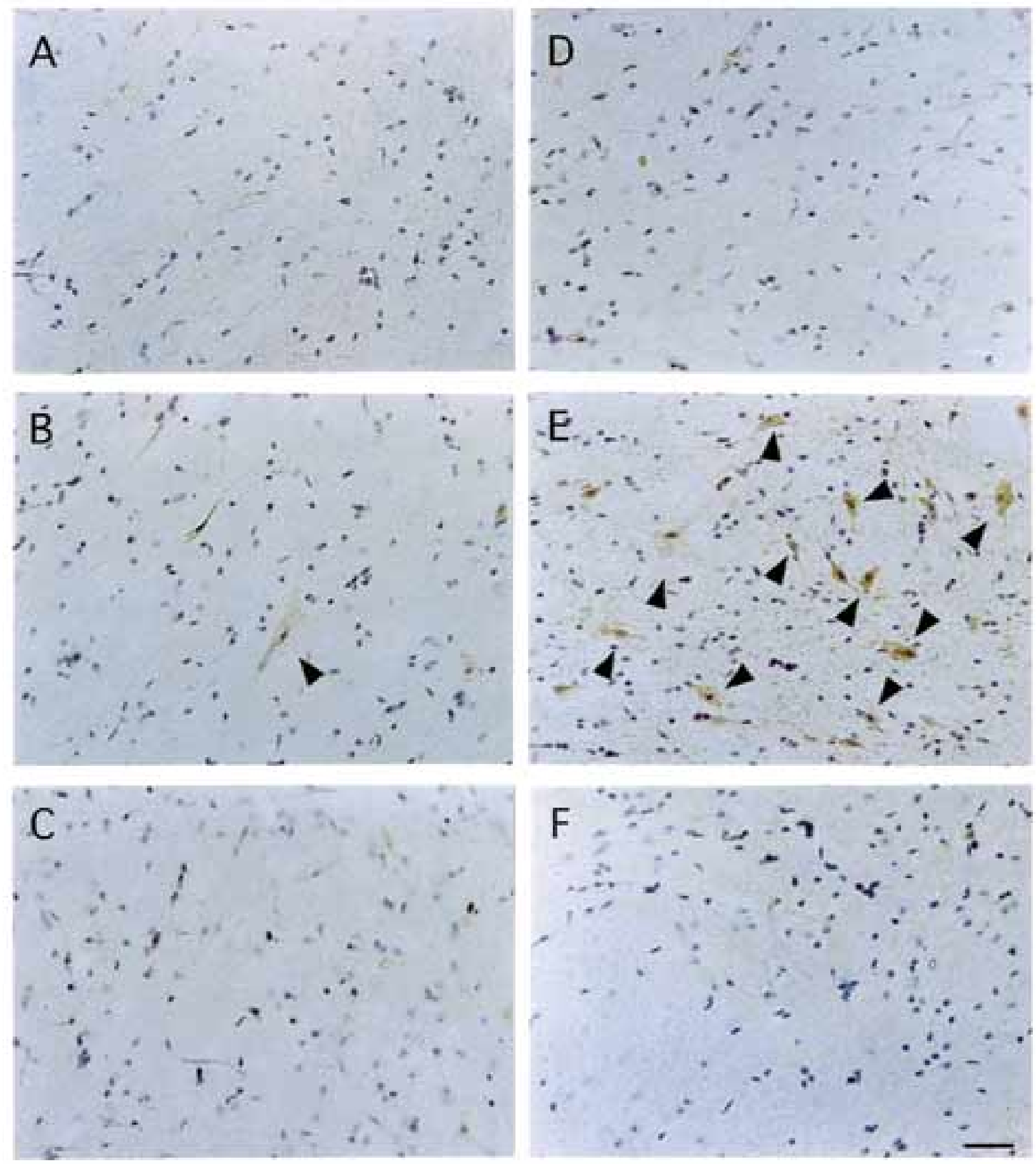

Fig 6. Immunostaining against caspase- 3 in motor neurons in the GDNF- or lacZ-treated groups in a sham-operated spinal cord (A and $\mathbf{D})$, at 8 hours $(\mathbf{B}$ and $\mathbf{E})$, and 1 day $(\mathbf{C}$ and $\mathbf{F})$ of reperfusion following 15 minutes of ischemia. Arrowheads show a motor neuron expressing immunoreactive caspase-3. Bar $=100 \mu \mathrm{m}$. 
express the GDNF gene as a functional protein in ischemic spinal cord. This may be because the GDNF gene is relatively small $(<700 \mathrm{bp})$ and the adenoviral vector locates in the episomal position but is not incorporated in the genome-like retroviral vectors. This may also be due to a mild reduction in protein synthesis in the case of ischemia, and no or only a minimal protein expression may be well correlated to the complete inhibition of protein synthesis associated with calcium overload after reperfusion. $\mathrm{We}^{16}$ previously demonstrated that the motor neurons of the ventral horn could effectively express the lacZ gene as a functional protein in ischemic spinal cord.

Caspase-3 (CPP32) is a member of the interleukin 1 converting enzyme-like proteases, which are related to mammalian apoptosis and inflammation..$^{30}$ Our previous study showed that an increase in the immunoreactivity of apoptosis-inducing protein, caspase-3, was demonstrated in the motor neuron cells of the spinal cord after 15 minutes of transient ischemia, and the peak immunostaining intensity of caspase- 3 after the ischemic insult preceded the DNA fragmentation in the spinal cord. ${ }^{17}$ This finding suggests that overexpression of caspase-3 may play an important role in the induction of DNA fragmentation in the spinal cord. The expression of caspase- 3 precedes the appearance of neuronal damage and may therefore be implicated in the activation of apoptosis. ${ }^{17}$ In this study, the GDNFtreated group showed a reduction in the number of TUNEL- and caspase-3-positive motor neuron cells. These results suggest that GDNF may play a protective role against spinal cord ischemia in rabbits and that the reduction of motor neuron death by GDNF is greatly associated with a reduction in DNA fragmentation and apoptotic signals of the caspase-3 cascade. Furthermore, our study is the first report that demonstrated gene therapy for spinal cord ischemia.

In summary, we demonstrated the transfer and expression of GDNF in motor neuron cells and the protective effect of GDNF on spinal cord ischemia with a reduction in the apoptotic process. Therefore, GDNF could become a strong candidate for a use as a therapeutic agent in the treatment of ischemic spinal cord injury in the near future.

We thank N. Ogoshi and J. Martin for their excellent technical assistance.

\section{REFERENCES}

1. Grossi EA, Krieger KH, Cunningham JN Jr, Culliford AT, Nathan IM, Spencer FC. Venoarterial bypass: a technique for spinal cord protection. J Thorac Cardiovasc Surg 1985;89:228-34.
2. Cambria RP, Davison JK, Zannetti S, L'Italien G, Brewster DC, Gretler JP, et al. Clinical experience with epidural cooling for spinal cord protection during thoracic and thoracoabdominal aneurysm repair. J Vasc Surg 1997;25:234-43.

3. Henderson CE, Phillips HS, Pollock RA, Davies AM, Lemeulle C, Armanini M, et al. GDNF: a potent survival factor for motor neurons present in peripheral nerve and muscle. Science 1994;266:1062-4.

4. Li IL, Wu W, Lin LFH, Lei M, Oppenheim RW, Houenou LJ. Rescue of adult mouse motor neurons from injury-induced cell death by glial-derived neurotrophic factor. Proc Natl Acad Sci U S A 1995;92:9771-5.

5. Lin LH, Doherty DH, Lile JD, Bektesh S, Collins F. GDNF: a glial cell line-derived neurotrophic factor for midbrain dopaminergic neurons. Science 1993;260:1130-2.

6. Beck KD, Valverde J, Alexi T, Poulsen K, Moffat B, Vandlen RA, et al. Mesencephalic dopaminergic neurons protected by GDNF from axotomy-induced degeneration in the adult brain. Nature 1995;373:339-41.

7. Wang Y, Lin SZ, Chiou AL, Williams LR, Hoffer BJ. Glial cell line-derived neurotrophic factor protects against ischemiainduced injury in the cerebral cortex. J Neurosci 1997;17:4341-8.

8. Kitagawa H, Hayashi T, Mitsumoto Y, Koga N, Itoyama Y, Abe $\mathrm{K}$. Reduction of ischemic brain injury by topical application of glial cell line-derived neurotrophic factor after permanent middle cerebral artery occlusion in rats. Stroke 1998;29:1417-22.

9. Abe K, Aoki M, Kawagoe J, Yoshida T, Hattori A, Kogure K, et al. Ischemic delayed neuronal death: a mitochondrial hypothesis. Stroke 1995;26:1478-89.

10. Aliki S, Caillaud C, Vigne E, Stratford-Perricaudet LD, Poenaru L, Perricaudet M, et al. Transfer of a foreign gene into the brain using adenovirus vectors. Nature Genet 1993;3:224-8.

11. Davidson BL, Allen ED, Kozarsky KF, Wilson JM, Roessler BJ. A model system for in vivo gene transfer into the central nervous system using an adenoviral vector. Nature Genet 1993;3:219-23.

12. Sakurai M, Abe K, Hayashi T, Warita H, Setoguchi Y, Itoyama Y, et al. In vivo adenovirus-mediated gene transfer and the expression in ischemic rabbit spinal cord. J Vasc Surg 1999;30:542-50.

13. Johnson SH, Kraimer JM, Graeber GM. Effect of flunarizine on neurological recovery and spinal cord blood flow in experimental spinal cord ischemia in rabbits. Stroke 1993;24:1547-53.

14. Setoguchi Y, Danel C, Crystal RG. Stimulation of erythropoiesis by in vivo gene therapy: physiologic consequences of transfer of the human erythropoietin gene to experimental animals using an adenovirus vector. Blood 1994;84:2946-53.

15. Abe K, Setoguchi Y, Hayashi T, Itoyama Y. In vivo adenovirusmediated gene transfer and the expression in ischemic and reperfused rat brain. Brain Res 1997;763:191-201.

16. Sakurai M, Hayashi T, Abe K, Sadahiro M, Tabayashi K. Delayed and selective motor neuron death after transient spinal cord ischemia: A role of apoptosis? J Thorac Cardiovasc Surg 1998;115:1310-5

17. Hayashi T, Sakurai M, Abe K, Sadahiro M, Tabayashi K, Itoyama Y. Apoptosis of motor neurons with induction of caspases on the spinal cord after ischemia. Stroke 1998;29;1007-13.

18. Sakurai M, Hayashi T, Abe K, Itoyama Y, Tabayashi K. Inductions of glial cell line-derived neurotrophic factor and Retlike immunoreactivities in rabbit spinal cord after transient ischemia. Neurosci Lett 1999;276:123-6.

19. Kondo T, Reaume AG, Huang TT, Carlson E, Murakami K, 
Chen SF, et al. Reduction of CuZn-superoxide dismutase activity exacerbates neuronal cell injury and edema formation after transient focal cerebral ischemia. J Neurosci 1997;17:4180-9.

20. Banner LR, Patterson PH. Major changes in the expression of the mRNAs for cholinergic differentiation factor/leukemia inhibitory factor and its receptor after injury to adult peripheral nerves and ganglia. Proc Natl Acad Sci U S A 1994;91:7109-13.

21. Choi-Lundberg DL, Bohn MC. Ontogeny and distribution of glial cell line-derived neurotrophic factor (GDNF) mRNA in rat. Dev Brain Res 1995;85:80-8.

22. Bradley WG. A phase I/II study of recombinant human brain-derived neurotrophic factor in patients with amyotrophic lateral sclerosis [abstract]. Ann Neurol 1995;38:971.

23. Haase G, Kennel P, Pettmann B, Vigne E, Akli S, Revah F, et al. Gene therapy of murine motor neuron disease using adenoviral vector for neurotrophic factors. Nature Med 1997;3:429-36.

24. Aebischer P, Schluep M, Deglon N, Joseph J, Hirt L, Heyd B, et al. Intrathecal delivery of CTNF using encapsulated genetically modified xenogeneic cells in amyotrophic lateral sclerosis patients. Nature Med 1996;2:696-9.
25. Petty BG, Cornblath DR, Adoranto BT, Chaudhry V, Flexner C, Wachsman $\mathrm{M}$, et al. The effect of systemically administered recombinant human nerve growth factor in healthy human subjects. Ann Neurol 1994;36:244-6.

26. Wolfe JH, Deshmann SL, Fraser NW. Herpes virus vector gene transfer and expression of b-glucuronidase in the central nervous system of MPS mice. Nature Genet 1992;1:379-84.

27. Heistad DD, Faraci FM. Gene therapy for cerebral vascular disease. Stroke 1996;27:1688-93.

28. Ono T, Fujino T, Tsuchiya M, Tsuda M. Plasmid DNAs directly injected into mouse brain with lipofectin can be incorporated and expressed by brain cells. Neurosci Lett 1990;117:7-13.

29. Price J, Turner D, Cepko C. Lineage analysis in the vertebrate nervous system by retrovirus-mediated gene transfer. Proc Natl Acad Sci U S A 1987;84:156-60.

30. Fernandes-Alnemri T, Litwack G, Alnemri ES. CPP32, a novel human apoptotic protein with homology to Caenorhabditis elegans cell death protein Ced-3 and mammalian interleukin1b-converting enzyme. J Biol Chem 1994;269:30761-4. 